\title{
PECULIARITIES OF DISTANCE MEDICAL LEARNING DURING THE COVID 2019 LOCKDOWN: PRACTICAL EXPERIENCE OF TEACHING MEDICAL ENGLISH
}

DOI: 10.36740/WLek202108132

\author{
Lesya Lymar, Khrystyna Storozhuk \\ O.BOGOMOLETS NATIONAL MEDICAL UNIVERSITY, KYIV, UKRAINE
}

\begin{abstract}
The aim: To define peculiarities of the medical students and medical PhD students' distance learning, basing on the academic performance and survey results.

Materials and methods: Forty-two medical students and thirty-eight PhD students of 0 .Bogomolets National medical university were randomly chosen for the study. Students' knowledge of English was initially " live" assessed in February, online assessments were held in April and May, concluded with the credit final assessment. Upon passing the final test the students were asked to fill in the questionnaire containing the following items: satisfaction with the distance learning, level of the distance learning hardness, comparison of distance learning by quality and understanding, choosing the best sections for the English distance learning, level of technical problems.

Results: All students during the 2020 distance learning have improved their English language level: the medical students from 3.8 to 3.99, the PhD students- from 4.36 to 4.56. The questioning of both groups showed significant dissatisfaction of medical students ( $52-57 \%$ by different positions) with the distance learning. The PhD students showed higher satisfaction level (76-86\% by different positions).

Conclusions: The assessed groups of the 0.Bogomolets National medical university improved their English knowledge level during the distance learning. The authors relate significant dissatisfaction of medical students with the distance learning to their low motivation and learning maturity. The PhD students' higher satisfaction level may be related to the wider variability of the issues to study. The problem of distance learning of both medical and PhD students should be studied more thoroughly.
\end{abstract}

KEY WORDS: medical students, PhD students, Medical English, distance learning

Wiad Lek. 2021;74(8):1964-1969

\section{INTRODUCTION}

The COVID 2019 lockdown led to significant changes in education of many countries, particularly in Ukraine. The order of the Cabinet of Ministers ordered total lockdown starting from the $11^{\text {th }}$ of March. According to the order, all education in secondary and higher school establishments was realized as a distance or on-line one. In secondary schools the "live" education wasn't restored by the end of the term, while in certain regions with descending COVID incidence it was permitted by the Ministry to hold education activities in groups not more than 10 people since the $1^{\text {st }}$ of June, mostly with purpose of examination. In fact, in Ukraine during 3 months all students studied distantly, which is a unique experience for the country. The further possibility of similar lockdown due to the second wave of COVID and further distant learning in 2020-2021 academic year necessitate the analysis of the spring 2020 distance learning organization, defining its peculiarities in Ukraine.

The notion of distance learning has been studied by numerous authors, though it has attained particular importance in March 2020. Moore, J. L et al states that in the 80s, distance learning was mentioned as learning "from the distance", without the direct contact of teacher and student[1]. There is a difference between distance learning and distance education, the first considered as a possibility, and second - as a result. Mojtahedzadeh, R et al dwell on the difference between the online-learning and e-learning [2], the notions being so close that some authors merge them [3] E-learning is more often associated with using various electronic devices( PC, laptop, plate, mobile phone), accessing the offered sources and performing the required tasks [4], while the online learning requires direct presence and communication with a teacher online [5] . Galusha, J. M. was the first to analyze the main drawbacks and barriers of distance learning, regarding technical, methodological and psychological issues[6]. Tavangarian, D., et al state that the e-learning may be considered as a separate direction of individual learning, which in future will become the only individual learning direction[7]. Simpson, O. [8]) and Bouhnik, D. [9] seem to be more focused on positive outcomes of the distance learning and methods of engaging students into a more profound activity. Rumble, G. [10]focuses exactly on the financial cost and organizing the distance learning. Clark, R. C., \& Mayer, R. E. [11]presented a guide for the distance learning teachers and software developers, analyzing in their study all possible fails of such learning. Levy, S. [12] analyzes mostly methodical peculiarities of distance learning, providing the reader with instructions and recommendations, pointing 
that the distance learning is the learner-centered- while the classical classroom learning is the instructor-centered. Zhang, D et al [13]considered an important question if the online learning, being "at an early stage" at that time period can change totally the so-called live direct learning and found this learning type fully promising.

Medical education has always stood apart from all the other education systems, regarding high responsibility of the graduates and requirements to their knowledge. In Ukraine, the medical educational institutions are supervised by both Ministry of Science and Ministry of Health of Ukraine. There is no part-time medical organization schedule in Ukraine, except for the pharmaceutical education, so the experience of distance learning was totally new. Lempp, H., \& Seale, C.[14], having analyzed medical curriculums, agree that the division of the study course into the more "theoretical" and "practical" course is reasonable, as the medical studies require direct engagement of the students. Steinert, Y. et al.[15], analyzing attempts to advance the medical learning curriculum, agree that the education should be more student-centered. The peculiarities of medical learning depending on the age and gender peculiarities were studied by Omelchuk, S [16], while the age aspect within the peer teaching was considered by $\mathrm{Yu}, \mathrm{T}$. $\mathrm{C}$ et al[17]. This presents a significant importance regarding the new learning methods, particularly the e-learning and online learning, as the elderly students show slower patterns of cognition than the younger ones. Bin Mubayrik $\mathrm{H}$. $\mathrm{F}$ particularly stopped at the motivation and perception of the medical students regarding distance learning, stressing on the stigmas against not "live" learning and poor motivation[18]. Wong, G.[19] and Kim, S. [20] having assessed the distance and e-learning effectiveness for the medical studies, state that the approach is full promising, though nothing can substitute live classroom presence.

The above-mentioned studies of the distance learning and implementation of the distance learning into the medical students' curriculum were made before the March 2020, when the COVID 2019 lockdown suddenly disrupted traditional perception of medical education system, particularly in Ukraine. Prohibition of any public activities, lectures or practical seminars with simultaneous strict measures wasn't immediately followed by the Ministry regulations on further organization of medical education, but the general, rather vague recommendations. Medical education was provided by the e-platform of each medical university, on which the tutors uploaded their materials, represented as the lectures, educational videos, study guides, protocols, tasks and tests, etc. The practical and seminar classes were held online through such programs as Skype, Zoom, Duo, Viber Video, etc. Due to technical failure of the educational platforms in the very first days of distant learning, some teachers offered the students to submit the performed tasks onto their email or any messenger ( What's App, Viber, Telegram), not through the platform, and some found this more convenient than the platform. In the end of each course studied by the medical students via the distant learning the students took examinations online. The postgraduate medical education was also held online, without the live classes. It was only starting from the $1^{\text {st }}$ of June, that the credit classes were allowed to be held, in groups of 10 people.

The authors considered such unique experience of teaching medical students and the $\mathrm{PhD}$ students online to be rather interesting for analyzing its peculiarities, in order to see the weak and strong points of such education.

\section{THE AIM}

To define peculiarities of the medical students and medical $\mathrm{PhD}$ students' distance learning, basing on the academic performance and survey results.

\section{MATERIALS AND METHODS}

To study the efficiency of the distance learning the authors have randomly chosen 42 medical $2^{\text {nd }}$ year students and 38 medical PhD students studying the course of Foreign language(English): respectively, the "English for Professional Purposes" and "Academic English for Medical PhDs" course in O.Bogomolets National medical university. The students were informed of their participation in the study and they gave oral consent on the participation.

Students' knowledge was assessed in the start of the term (in February) by the introducing test. The students studied English once a week, with the seminar class duration of 3 academic hours. Starting with the $11^{\text {th }}$ of March, all education was performed online. Both $2^{\text {nd }}$ year and $\mathrm{PhD}$ students received class guides with the defined volume of tasks and video-explanation. The teachers provided for the feedback online, using Skype videoconference software, and the University platform. In the end of April and middle of May the students took the tests to check their comprehension of the material. Upon completing the course, the students took the credit ( the $2^{\text {nd }}$ year students- online, the $\mathrm{PhD}$ students- in live communication).

The assessment of the students' knowledge was organized as follows:

1. Introducing test ( written during 30 minutes in a classroom). The test results were assessed by a 4 -point scale.

2. Monthly student tests, including the tasks on the same sections, estimated by a 4-point-scale. The February test was written in a classroom, while in April and May similar tests were written online, the teachers controlling the environment around the testee using the camera.

3. Final credit task, including both written test with the "vocabulary", "grammar" and "writing" sections and the personal interview on the studied material comprehension. To simplify the calculations, the authors represent the credit class mark in a 4-point-system, which is a mean average of all 4 activities results tested during the credit class.

On the final credit class, both $2^{\text {nd }}$ year and $\mathrm{PhD}$ students were asked to fill in the following questionnaire:

1. Express your satisfaction with the distance learning, choosing the options: "more than satisfied", "satisfied", "insufficiently satisfied", "totally disappointed". 
2. Studying online was for you: "easier than live classes", "the same as live classes", "harder than live classes".

3. You have learnt with the distance learning: "better and more material than before the lockdown", "the same amount and quality of material", "less material with worse understanding than before the lockdown".

4. The best for the distance learning for you was: "vocabulary", "grammar", "reading", "listening", "speaking" sections, "all sections were the same".

5. How often did you experience technical problems studying online: "often", "sometimes", "never".

All the surveyed gave oral consent for participation in the study. The statistical data were processed using the STATISTICA 17.0 software.

\section{RESULTS}

The results of the medical and PhD students' academic initial English language testing are represented in table I. They evidence about rather high initial English language knowledge level, particularly by the $\mathrm{PhD}$ students. As for the medical students, they showed weak results in the writing section.

The students studied in February and first half of March by the traditional system, and after the $11^{\text {th }}$ of March-online. The results of their April and May testings are represented in table II.

As the table shows, all students during their lockdown distance learning have improved their English language level, which is particularly evident in the $\mathrm{PhD}$ students, with the most significant improvement in the vocabulary section: starting from the mean average mark of 4.25 to 4.75 after three months. Here the results of March and April are intentionally offered in one table, so as to show the direct achievements of the distance learning, the shift from March to April. Both groups showed slight improvement in the writing section. Though, as for the grammar in use section, the medical students showed considerable shift in the last month. Totally, the general knowledge level of medical students improved from 3.8 to 4.15, which corresponds to total "good mark". The general knowledge of the $\mathrm{PhD}$ students level improved from 4.36 to 4.61 . The results of the final evaluation are shown in table III.

So, the mean average mark of the chosen medical students group is 3.99 , which is slightly less than the average mark of last testing (4.15), but anyway higher than the initial testing mark (3.8). As for the PhD students, their average mark(4.56) is also slightly lower than the last testing mark(4.61), though it almost coincides with the pre-last testing mark, exceeding the initial average mark (4.36). All this evidences about effectiveness of distance education.

The students' survey results were rather direct. As for the question where they were asked to express their satisfaction with distance learning, $42.1 \%$ of the $\mathrm{PhD}$ students and $26 \%$ of medical students chose the option "more than satisfied", and $38 \%$ of the $\mathrm{PhD}$ students and $17 \%$ of medical students were satisfied" $(\mathrm{P}<0.05)$. So, totally $19.9 \%$ of the $\mathrm{PhD}$ students and almost $57 \%$ of medical students didn't express sufficient satisfaction with their distance studies. The results of the $\mathrm{PhD}$ students survey ( almost $20 \%$ of the $\mathrm{PhD}$ students weren't satisfied) showed a significant room for improvement of the distance learning course.

Comparing the live and distance classes, $52 \%$ of medical students and $14 \%$ of $\mathrm{PhD}$ students stated that it was "harder than the live classes", $26 \%$ of medical and $44 \%$ of $\mathrm{PhD}$ students stated that it was "the same as live classes by hardness" and $22 \%$ of medical and $42 \%$ of $\mathrm{PhD}$ students noted that it was "easier than live classes". The observed complaints correspond to the dissatisfaction level in the previous question.

As for comparing the live and distant learning by the parameters "quality and volume of material", $45 \%$ of the $\mathrm{PhD}$ and $22 \%$ of medical students stated that they learned "better and more material than before the lockdown", $42 \%$ of the PhD and $30.1 \%$ of medical students chose the option "the same amount and quality of material", and $13 \%$ of the $\mathrm{PhD}$ and $47.9 \%$ of medical students claimed they studied "less material with worse understanding than before the lockdown". The last numbers, compared to the dissatisfaction level show that initial dissatisfaction wasn't based only on poor quality of teaching and poor material understanding. Totally, half of the medical students were concerned about their knowledge.

The results of self-evaluation of English mastering level are represented in table IV.

Mentioning the technical problems online, $48 \%$ of the $\mathrm{PhD}$ students and $64 \%$ of medical students mentioned that they "often" had technical problems". Twenty-five per cent of the $\mathrm{PhD}$ students and $31 \%$ of medical students "sometimes" had similar difficulties, and only $17 \%$ of the $\mathrm{PhD}$ and $5 \%$ of medical students "never" had any technical problems with distance learning.

\section{DISCUSSION}

The received results evidence about efficiency of the medical students and PhD students English course distance learning. The analysis of the initial testing results evidences about higher knowledge and higher learning motivation of the PhD students compared to the medical students. It's evident that the $\mathrm{PhD}$ students have already completed their medical studies and are determined to continue their research. Medical students, who study English during their $2^{\text {nd }}$ year, aren't so experienced, hence, determined to learn foreign language. The $\mathrm{PhD}$ students outgo medical students in their knowledge. So, the difference in the initial knowledge level shows better knowledge of the $\mathrm{PhD}$ students, and, probably, their better motivation for learning. The results of the intermediate testing show us how the students studied during the distance learning period. Generally, there is overall slow improvement in English. It is noteworthy, that the medical students during the lockdown have improved their grammar knowledge and writing skills ( 4.4 against 4.05 and 3.95 against 3.6 respectively) while the PhD students were more successful in vocabulary section(4.75 against 4.25$)$. This may be attributed 
Table I. Mean average points in initial medical English testing

\begin{tabular}{ccccc}
\hline & $\begin{array}{c}\text { Vocabulary in use( in } \\
\text { 4-point system) }\end{array}$ & $\begin{array}{c}\text { Grammar in use( in } \\
\text { 4-point system) }\end{array}$ & $\begin{array}{c}\text { Writing section } \\
\text { ( in 4-point system) }\end{array}$ & $\begin{array}{c}\text { Total mark } \\
\text { Medical students }\end{array}$ \\
\hline PhD students & 3.8 & 4.05 & 3.6 & 3.8 \\
\hline
\end{tabular}

Table II. Mean average points in March and April testing

\begin{tabular}{ccccc}
\hline & $\begin{array}{c}\text { Vocabulary in use( in } \\
\text { 4-point system):April/ } \\
\text { May }\end{array}$ & $\begin{array}{c}\text { Grammar in use( in } \\
\text { 4-point system): April/ } \\
\text { May }\end{array}$ & $\begin{array}{c}\text { Writing section } \\
\text { ( in 4-point system): } \\
\text { April/May }\end{array}$ & $\begin{array}{c}\text { Total mark: } \\
\text { April/May }\end{array}$ \\
\hline Medical students & $3.9 / 4.1$ & $4.12 / 4.4$ & $3.8 / 3.95$ & $3.94 / 4.15$ \\
\hline PhD students & $4.66 / 4.75$ & $4.4 / 4.5$ & $4.6 / 4.6$ & $4.55 / 4.61$ \\
\hline
\end{tabular}

Table III. Final evaluation results expressed in 4 points( mean average)

\begin{tabular}{cc} 
& Final credit evaluation (mean average) \\
\hline Medical students & 3.99 \\
\hline PhD students & 4.56 \\
\hline
\end{tabular}

Table IV. The best section for online studies

\begin{tabular}{|c|c|c|c|c|c|c|}
\hline & Vocabulary, \% & Grammar, \% & Reading, \% & Listening, \% & Speaking, \% & $\begin{array}{c}\text { all sections were } \\
\text { the same, } \%\end{array}$ \\
\hline Medical students & $38 \%$ & $26 \%$ & 18.1 & $2.8 \%$ & $4.1 \%$ & $11 \%$ \\
\hline PhD students & $23.4 \%$ & $15.7 \%$ & $35 \%$ & $10.1 \%$ & $8.8 \%$ & $7 \%$ \\
\hline
\end{tabular}

to doing many written exercises offered on the platform, which the learners didn't manage to do before, due to lack of time and lack of resources. The $\mathrm{PhD}$ students' progress in writing was the least considerable. We try to explain it by the already high level of writing shown by the students and higher motivation to improve other sections. As a $\mathrm{PhD}$ student said, "At last we have time to complete and outdo everything we couldn't before". This raises another question of extensive medical and postgraduate curriculum, balance of education and free time and rationalizing the schedule. In general, the results of the May testing show that both $\mathrm{PhD}$ and medical students improved their knowledge level. The testing was written by the students online, with the least possibility of cheating. The results of the final credit estimation showed that the distance learning turned to be rather successful. All students successfully passed the credit. The observed results are better than those shown at the initial testing, but somehow worse than those of the last May testing: for medical students, the final average point for the course was 3.99 compared to the initial 3.8, with April result of 3.94 and May result of 4.15.This difference may be explained by stressful situation of the examination, and low probability of cheating. As for the $\mathrm{PhD}$ students result, they also showed rather high academic progress, with the initial 4.36 points compared to the increasing in April (4.55) and May(4.61) achievement level, and the final mark which only slightly lagged behind the May one(4.56). In both groups April mark almost coincides with the final one, though the progress of the $\mathrm{PhD}$ students was better. Another issue that may predispose for the final mark lower than that of May testing is that the credit evaluation demanded thorough knowledge of all themes studied during the term.

The results of the survey of both medical and $\mathrm{PhD}$ students showed certain problems of distance learning. Certain share of the $\mathrm{PhD}$ and much greater that of medical students is totally unsatisfied with their distance learning, despite the total high achievements. Medical students confirmed that the distance studies were harder than the live ones ( $52 \%$ ) while almost the same amount of the $\mathrm{PhD}$ students stated(42\%) that they were much easier. Here we encounter with a totally different educational paradigm, where the PhD students are "dreaming" of more free time and the opportunity to structure their time on their wish, and the medical students desperately crave for attending live classes and being strictly led by a tutor at the live classes. The authors suppose this to be the main conclusion: medical students of the first years aren't independent enough to take responsibility for their studies and motivation, while the PhD students turn out to be sufficiently mature for this, which affects their academic achievements.

The distribution of the "best" language sections choice confirms this, as, the medical students chose the sections common for the "read-translate-learn-control" learning type, the vocabulary and grammar. The preferences distribution shown by the PhD students doesn't show such striking differences, even speaking tasks ( done and controlled online) were chosen by $8.8 \%$. The choice of the "listening" task ( $2.8 \%$ for medical students vs 10.1 for $\mathrm{PhD}$ students) also confirms our hypothesis of maturity and 
independent learning position, as it required perseveration and determination to learn.

As for the technical difficulties issue, the objective situation of the distance course learning was a novelty, and the university server administrators weren't ready for such simultaneous "overflow" of courses, teachers and students on the site. In addition to this, individual problems of the Internet providers in Ukraine should be also mentioned. So, it is rational to admit there were technical problems with distance learning. But the attitude to the problems shows significantly higher dissatisfaction of the medical students with the system than the $\mathrm{PhD}$ expressed.

All the obtained results evidence about low learning maturity of the first year medical students, their low readiness to take responsibility for their education on themselves and low learning motivation. The survey results of the medical students are more about complaining than about critical analysis, though the academic achievement marks are rather high. The results of the $\mathrm{PhD}$ students show their sufficient readiness to study online, determination for the studies and high motivation level. It is possible to "read behind the lines" about some problems of distance learning which were experienced by both groups, that need improvement, such as :technical provision quality, direct guidance of the tutors, etc.

\section{CONCLUSIONS}

Distance learning of medical students is a rather controversial issue. On one side, the responsibility for the patients' lives goes contrary to obtaining knowledge behind the computer screen. On another side, the curriculum of medical students is overfilled with information, and the issue of free time becomes of particular importance for the students. The medical students and $\mathrm{PhD}$ students distance learning of many courses in spring 2020 due to the COVID lockdown turned out to be successful, particularly that one of medical English. The assessed groups of the O.Bogomolets National medical university improved their knowledge level during the studies, which was confirmed by their academic achievement results. The questioning of both groups showed significant dissatisfaction of medical students with the distance learning, which, due to a number of factors, the authors relate more not to the problems of distance learning in the university, but to their low motivation and learning maturity. The $\mathrm{PhD}$ students showed higher satisfaction level, characterizing distance learning more positively, particularly due to the free time and wider variability of the issues to study. Obviously, the problem of distance learning of both medical and $\mathrm{PhD}$ students should be studied more thoroughly, regarding both time economy and possible second COVID wave lockdown issues.

\section{REFERENCES}

1. Moore J., Dickson-Deane C., Galyen K. e-Learning, online learning, and distance learning environments: Are they the same?. The Internet and Higher Education. 2011; 14.2: 129-135. doi: 10.1016/j. iheduc.2010.10.001.
2. Mojtahedzadeh R., Mohammadi A., Emami A. Comparing live lecture, internet-based \& computer-based instruction: a randomized controlled trial. Medical journal of the Islamic Republic of Iran. 2014; 28: 136.

3. PorterL.Creatingthevirtual classroom:Distancelearning withtheInternet. John Wiley \& Sons, Inc. 1997. doi: 10.1177/105065199901300106.

4. Horton W. E-learning by design. John Wiley \& Sons. 2011, 311p.

5. Diaz D., Cartnal R. Students' learning styles in two classes: Online distance learning and equivalent on-campus. College teaching. 1999; 47.4: 130-135. doi: 10.1080/87567559909595802.

6. Galusha J. Barriers to learning in distance education. 1998. 411p.

7. Tavangarian D., Leypold M., Nölting K. et al. Is e-Learning the Solution for Individual Learning? Electronic Journal of E-learning, 2004; 2.2: 273-280.

8. Simpson 0. Supporting students in online, open and distance learning. Routledge. 2018, 237p.

9. Bouhnik D., Marcus T. Interaction in distance-learning courses. Journal of the American Society for Information Science and Technology. 2006; 57.3: 299-305.

10. Rumble $G$. The costs and economics of open and distance learning. Routledge. 2002, 237p.

11. Clark R., Mayer R. E-learning and the science of instruction: Proven guidelines for consumers and designers of multimedia learning. John Wiley \& Sons, 2016. doi: 10.1002/bmb.2003.494031039994.

12. Levy S. Factors to Consider When Planning Online Distance Learning Programs in Higher Education. Online Journal of Distance Learning Administration, Spring. 2003.

13. Zhang D., Zhao J., Zhou L. et al. Instructional video in e-learning: Assessing the impact of interactive video on learning effectiveness. Information \& management. 2006; 43.1: 15-27. doi: 10.1016/j. im.2005.01.004.

14. Lempp H., Seale C. The hidden curriculum in undergraduate medical education: qualitative study of medical students'perceptions of teaching. Bmj. 2004; 329.7469: 770-773. doi: 10.1136/bmj.329.7469.770.

15. Steinert Y., Mann K., Centeno A. et al. A systematic review of faculty development initiatives designed to improve teaching effectiveness in medical education: BEME Guide No. 8. Medical teacher. 2006; 28(6): 497-526. doi: 10.1080/01421590600902976.

16. Omelchuk S., Lymar L. Gender and professional factors of medical students' psychological treadiness for performing professional duties. Georgian medical news. 2016; 251: 45-50.

17. Yu T., Wilson N., Singh P. et al Medical students-as-teachers: a systematic review of peer-assisted teaching during medical school. Advances in medical education and practice. 2011;2: 157. doi: 10.2147/AMEPS14383.

18. Bin Mubayrik H. Exploring Adult Learners'Viewpoints and Motivation Regarding Distance Learning in Medical Education. Advances in Medical Education and Practice. 2020; 11: 139. doi: 10.2147/AMEP.S231651.

19. Wong G., Greenhalgh T., Pawson R. Internet-based medical education: a realist review of what works, for whom and in what circumstances. BMC medical education. 2010; 10(1): 1-10. doi: 10.1186/1472-6920-10-12.

20. Kim S. The future of e-learning in medical education: current trend and future opportunity. Journal of educational evaluation for health professions. 2006; 3. D0l: 10.3352/jeehp.2006.3.3.

\section{ORCID and contributionship:}

Lesya Lymar: 0000-0002-9407-1066 A,B,D,F

Khrystyna Storozhuk: 0000-0003-3897-5930 B,C,E

\section{Conflict of interest:}

The Authors declare no conflict of interest. 


\section{CORRESPONDING AUTHOR}

\section{Lesya Lymar}

0.Bogomolets National Medical University

34 Peremohy av., 02000 Kyiv, Ukraine

tel: +380954373333

e-mail: lesyalymar@ukr.net

Received: 13.08 .2020

Accepted: 02.06 .2021

A - Work concept and design, B - Data collection and analysis, C - Responsibility for statistical analysis,

$\mathbf{D}$-Writing the article, $\mathbf{E}$-Critical review, $\mathbf{F}$ - Final approval of the article 